\title{
NONLINEAR DYNAMIC ANALYSIS BASED ON EXPERIMENTAL DATA OF RC TELECOMMUNICATION TOWERS SUBJECTED TO WIND LOADING
}

\author{
MARCELO A. SILVA AND REYOLANDO M. L. R. F. BRASIL
}

Received 15 January 2005; Revised 27 March 2006; Accepted 4 April 2006

The goal of this paper is to propose a nonlinear dynamic model based on experimental data and NBR-6123-87 to accomplish a nonlinear dynamic analysis of slender structures subjected to wind loading. At first we compute the static answer given by the mean wind speed. In this part of the problem we consider the concept of effective stiffness to represent the physical nonlinearity of material and a $P$-Delta method to represent the geometrical nonlinearity. Considering the final stiffness obtained in that $P$-Delta method, we compute the dynamic answer given by the floating wind speed, according to the discrete dynamic model given by NBR-6123-87. A $40 \mathrm{~m}$ RC telecommunication tower was analyzed, and the results obtained were compared with those given by linear static and dynamic models.

Copyright (c) 2006 M. A. Silva and R. M. L. R. F. Brasil. This is an open access article distributed under the Creative Commons Attribution License, which permits unrestricted use, distribution, and reproduction in any medium, provided the original work is properly cited.

\section{Introduction}

The models proposed by the Brazilian code NBR-6123-87 [2] to accomplish a dynamic analysis of structures-subjected wind loading are based on linear dynamic models. In RC structures where the effective stiffness changes continuously due to nonlinear material behavior and the level of strength, linear models could not describe precisely the structure behavior. Computation of cross-sections properties, and consequently the displacements and internal loads, in slender RC structures subjected to wind loading is a very difficult task because as the loads change along time, cross-sections properties change too. Which stiffness do we consider? Wind speed is defined by two components, one is the mean wind speed and the other is the floating wind speed. Mean wind speed applies on the structures static loads, while floating wind speed applies on dynamic loading. The models given by NBR-6123-87 [2] are based on linear dynamic models, in other words, they consider a constant stiffness along time, what does not happen in practice.

Hindawi Publishing Corporation

Mathematical Problems in Engineering

Volume 2006, Article ID 46815, Pages 1-10

DOI 10.1155/MPE/2006/46815 


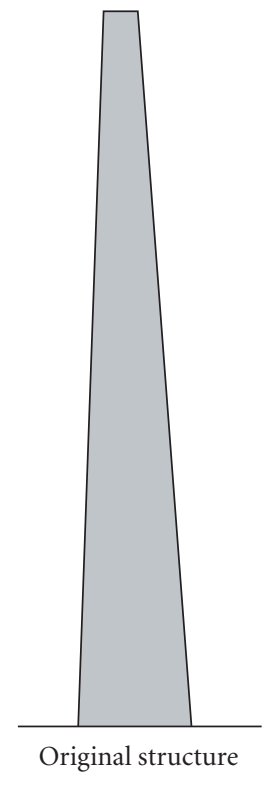

(a)

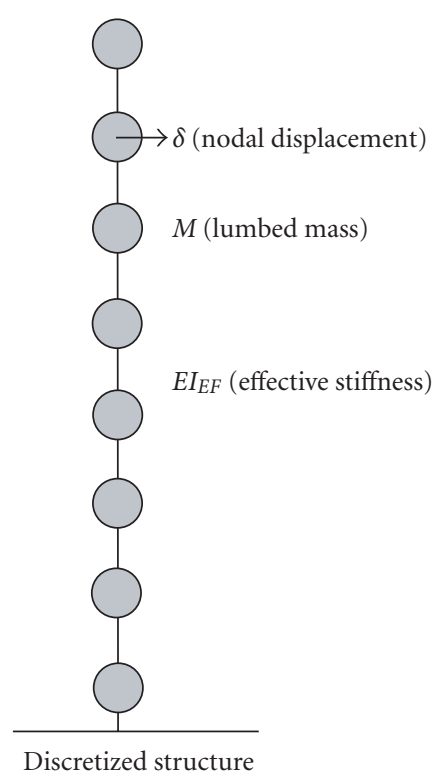

(b)

Figure 2.1. Typical RC telecommunication tower: original and discretized structure.

In this work the authors analyze a prefabricated $40 \mathrm{~m} \mathrm{RC}$ telecommunication tower (Figure 2.1) similar to others erected at Minas Gerais and Espírito Santo states of Brazil. For the effects of the mean wind speed on structure, the authors consider a nonlinear behavior. In this phase, a $P$-Delta effect will be considered on the structure. In each iteration, the effective stiffness is given by Brasil and Silva [1]. After this method of converging, we initiate the computation of the dynamic effects of wind given by the floating wind speed. The authors consider that the structure vibrates around an equilibrium position. This position is that one given by the last iteration of the $P$-Delta method. Then, the natural modes and frequencies of vibration are computed considering the effective stiffness given by the last iteration of $P$-Delta method. Once the natural shapes and frequencies are known, the dynamic analysis can be done according to NBR-6123-87 [2]. The sum of the static, given by $P$-Delta method with Brasil and Silva [1] curves, and dynamic components, provided by the discrete dynamic model of NBR-6123-87 [2], gives the structure behavior.

\section{Nonlinear dynamic analysis}

2.1. Linear static analysis (LSA). According to NBR-6123-87 [2], $V_{0}$ (meters per second) is the mean wind speed computed on 3 seconds, at 10 meters above ground, at a plain terrain with no roughness, and with recurrence of 50 years. The topographic factor is $S_{1}$, 
while the terrain roughness is given by factor $S_{2}$, which is a function given by

$$
S_{2}=b F_{r}\left(\frac{z}{10}\right)^{p}
$$

where $b, p$, and $F_{r}$ are factors which depend on the terrain characteristics, and $z$ is the height above the ground in meters. The statistic factor is $S_{3}$. Both $S_{1}, S_{2}$, and $S_{3}$ are given by tables in Brazilian code NBR-6123-87 [2]. The characteristic wind speed (meters per second) and the wind pressure (Pascal) are, respectively,

$$
V_{k}=V_{0} \cdot S_{1} \cdot S_{2} \cdot S_{3}, \quad q=0.613 \cdot V_{k}^{2} .
$$

The wind load (Newton) on an area $A$ (projection on a vertical plane of a given object area in square meters) is computed as

$$
F=q \cdot C_{a} \cdot A,
$$

where $C_{a}$ is the aerodynamical coefficient. The Brazilian code NBR-6123-87 [2] presents tables for $C_{a}$ values.

2.2. Linear dynamic analysis (LDA). According to NBR-6123-87 [2], for the $j$ th degree of freedom, the total load $X_{j}$ due to direct along wind is the sum of the mean and floating load given by

$$
X_{j}=\bar{X}_{j}+\hat{X}_{j}
$$

where the mean load $\bar{X}_{j}$ is

$$
\bar{X}_{j}=\bar{q}_{o} b^{2} C_{j} A_{j}\left(\frac{z_{j}}{z_{r}}\right)^{2 p}
$$

given

$$
\bar{q}_{o}=0.613 \bar{V}_{p}^{2}, \quad \bar{V}_{p}=0.69 V_{0} S_{1} S_{3} \quad\left(q_{o} \text { in } \mathrm{N} / \mathrm{m}^{2}, \bar{V}_{p} \text { in } \mathrm{m} / \mathrm{s}\right),
$$

$b$ and $p$ are indicated [2, Table 20 of NBR-6123-87]; $z_{r}$ is the level of reference, equal to 10 meters in this work; and $\bar{V}_{p}$ is the design wind speed corresponding to the mean speed during 10 minutes at 10 meters above the ground level, for a terrain roughness $\left(S_{2}\right)$ category II.

The floating component $\hat{X}_{j}$ is given by

$$
\hat{X}_{j}=F_{H} \psi_{j} \varphi_{j}
$$

where

$$
\psi_{j}=\frac{m_{j}}{m_{o}}, \quad F_{H}=\bar{q}_{o} b^{2} A_{o} \frac{\sum_{i=1}^{n} \beta_{i} \varphi_{i}}{\sum_{i=1}^{n} \psi_{i} \varphi_{i}^{2}} \xi, \quad \beta_{i}=C_{a i} \frac{A_{i}}{A_{o}}\left(\frac{z_{i}}{z_{r}}\right)^{p},
$$


$m_{i}, m_{0}, A_{i}, A_{0}, \xi$, and $C_{a i}$ being, respectively, the lumped mass at the $i$ th degree of freedom, a reference mass, the equivalent area at the $i$ th degree of freedom, a reference area, the dynamic amplification coefficient [2, Figure 17 of NBR-6123-87], and the area $A_{i}$ aerodynamical coefficient.

Note that $\varphi=\left[\varphi_{i}\right]$ is a given mode of vibration. To compute $\varphi_{i}$ and $\xi$, it is necessary to consider the structure mass and stiffness. The lumped mass can be easily calculated by summing the mass around an influence region of the node. The total homogenized moment of inertia of the cross-section is given by

$$
I_{\text {total }}=I_{c}+I_{s \text { hom }}, \quad \text { where } I_{s \text { hom }}=I_{s}\left(\frac{E_{s}}{E_{c \sec }}-1\right), \quad E_{c s e c}=0.9 \times 6600 \sqrt{f_{c k}+3.5} \quad(\mathrm{MPa}),
$$

$E_{s}, E_{c s e c}, I_{s}, I_{s h o m}, I_{c}$, and $f_{c k}$ being, respectively, the elasticity modulus of steel, the secant elasticity modulus of concrete (NBR-6118-78 [3]), the moment of inertia related to the structure axis of the total longitudinal steel area, the homogenized moment of inertia of the longitudinal steel area, the moment of inertia of the total cross-section area, and the characteristic compressive resistance in MPa at 28 days concrete. Since this model is based on linear dynamic models, we consider the cross-section moment of inertia as the total stiffness, such as

$$
I=I_{\text {total }}
$$

of each section to compute stiffness matrix of the structure. This assumption may be justified because if this is a linear elastic model, any cross-section damage can be considered in this analysis, so the stiffness to be considered must be the total stiffness.

When $r$ modes are considered in the analysis, the combination of these modes, for a given dynamic variable $\widehat{Q}$, is computed as

$$
\widehat{Q}=\left[\sum_{k=1}^{r} \hat{Q}_{i}^{2}\right]^{1 / 2},
$$

and

$$
Y_{i}=\frac{1}{3} X_{i}
$$

is a transversal dynamic load.

2.3. Nonlinear dynamic analysis (NDA). As stated before, the loads due to the wind speed present two components: the static loads due to mean wind speed and the dynamic loads due to the floating wind speed. The static loads are computed as given in (2.5) and (2.6). We call the first results obtained using these equations as the first-order static internal loads. At this point, we consider that the structure under those static loads is subjected to the $P$-Delta effect. The static displacements $\left(\bar{\delta}_{i(j)}\right)$ at the $i$ th node and the $j$ th iteration of the $P$-Delta method are computed considering the effective stiffness. Differently of what occurs in Section 2.2, we consider the following expressions to compute 
the moment of inertia (Brasil and Silva [1]) at the $i$ th node and the $j$ th iteration of the $P$-Delta method:

$$
I_{i(j)}=I_{E F i(j)}=w_{i(j)} I_{\text {total } i}, \quad \text { where } w_{i(j)}=w\left(x_{i(j)}\right), \quad x_{i(j)}=\frac{\bar{M}_{k i(j-1)}}{M_{u i}}
$$

$I_{E F}, w, x, \bar{M}_{k}$, and $M_{u}$ being, respectively, the effective moment of inertia, the parameter of effective stiffness, the level of strength, the working bending moment due to mean wind speed, and the ultimate code-based moment of a given cross-section. In (2.13) we consider the damage that occurred in the cross-sections is represented by the effective stiffness concept.

Finally, the P-Delta effect is computed, at the $i$ th node and the $j$ th iteration of the $P$-Delta method, as

$$
\Delta \bar{M}_{k i(j)}=\Delta N_{k i}\left(\bar{\delta}_{i(j)}-\bar{\delta}_{i(j-1)}\right), \quad \bar{M}_{k i(j)}=\bar{M}_{k i(j-1)}+\sum_{l} \Delta \bar{M}_{k l(j)}
$$

We call the final results obtained using these equations as the second order static internal loads. Considering the stiffness obtained in the final iteration of $P$-Delta method we compute the modes and frequencies of the vibration of the structure and so accomplish the dynamic analysis, as described by (2.7) and (2.8). We considered that the structure displaces around the equilibrium position given by the $P$-Delta method.

\section{Structure analyzed and numerical results}

The structure analyzed here is an RC telecommunication tower $40 \mathrm{~m}$ long and with a diameter of $60 \mathrm{~cm}$. The structure is cylindrical with cross-section in circular ring. Properties change along the structure axis, because the thickness and steel area vary along the axis. The concrete used in the fabrication of the structure presents characteristic resistance $\left(f_{c k}\right)$ at 28 days equal to $45 \mathrm{MPa}$, which represents, according to (2.9), $E_{c \sec }=41.4 \mathrm{GPa}$. We consider the elasticity modulus of the structure $E=E_{c s e c}$. The concrete covering is $25 \mathrm{~mm}$. The concrete design resistance is $f_{c d}=45 / 1.3 \mathrm{MPa}$. The steel used in confection of the structure presents $f_{y d}=500 / 1.15 \mathrm{MPa}$ (steel design stress) and $E_{s}=210 \mathrm{GPa}$. The structure is discretized into 40 elements of one meter long each one. The properties are shown in Table 3.1.

In Table 3.1 we used the following notations: Node is the node number in the finite elements method (FEM) program; Height is the level related to the ground level; Øext is the external diameter of the cross-section; Thick is the thickness of the cross-section; $\mathrm{M}$ is the nodal mass (lumped mass); A total is the cross-section area; Ic is the moment of inertia of the circular ring; nb is the number of longitudinal bars of the reinforced concrete section; $\varnothing b$ is the diameter of longitudinal bars; As is the total longitudinal steel area; $\mathrm{Rb}$ is the radius of the circle that passes along the longitudinal bars axis; Is is the total moment of inertia of the steel area; I total is the total homogenized moment of inertia of the reinforced concrete cross-section; and Is/I total $=w s$ is the lower boundary value for $w$ in each section. 
Table 3.1. Structure properties.

\begin{tabular}{|c|c|c|c|c|c|c|c|c|c|c|c|c|c|}
\hline Node & $\begin{array}{c}\text { Height } \\
(\mathrm{m})\end{array}$ & $\begin{array}{l}\text { øext } \\
(\mathrm{cm})\end{array}$ & $\begin{array}{l}\text { Thick } \\
(\mathrm{cm})\end{array}$ & $\begin{array}{c}\mathrm{M} \\
(\mathrm{kgf})\end{array}$ & $\begin{array}{l}\text { A total } \\
\left(\mathrm{cm}^{2}\right)\end{array}$ & $\begin{array}{c}\text { Ic } \\
\left(\mathrm{cm}^{4}\right)\end{array}$ & $\mathrm{nb}$ & $\begin{array}{c}ø \mathrm{~b} \\
(\mathrm{~mm})\end{array}$ & $\begin{array}{c}\text { As } \\
\left(\mathrm{cm}^{2}\right)\end{array}$ & $\begin{array}{c}\mathrm{Rb} \\
(\mathrm{cm})\end{array}$ & $\begin{array}{c}\text { Is } \\
\left(\mathrm{cm}^{4}\right)\end{array}$ & $\begin{array}{l}\text { I total } \\
\left(\mathrm{cm}^{4}\right)\end{array}$ & $\begin{array}{l}\text { Is/I } \\
\text { total }\end{array}$ \\
\hline 1 & 40 & 60 & 10 & 802 & 1521 & 500417 & 20 & 13 & 25 & 27 & 8643 & 535650 & $7 \%$ \\
\hline 2 & 39 & 60 & 10 & 420 & 1521 & 500417 & 20 & 13 & 25 & 27 & 8643 & 535650 & $7 \%$ \\
\hline 3 & 38 & 60 & 10 & 420 & 1521 & 500417 & 20 & 13 & 25 & 27 & 8643 & 535650 & $7 \%$ \\
\hline 4 & 37 & 60 & 10 & 420 & 1521 & 500417 & 20 & 13 & 25 & 27 & 8643 & 535650 & $7 \%$ \\
\hline 5 & 36 & 60 & 10 & 420 & 1521 & 500417 & 20 & 13 & 25 & 27 & 8643 & 535650 & $7 \%$ \\
\hline 6 & 35 & 60 & 10 & 420 & 1521 & 500417 & 20 & 13 & 25 & 27 & 8643 & 535650 & $7 \%$ \\
\hline 7 & 34 & 60 & 10 & 420 & 1521 & 500417 & 20 & 13 & 25 & 27 & 8643 & 535650 & $7 \%$ \\
\hline 8 & 33 & 60 & 10 & 420 & 1521 & 500417 & 20 & 13 & 25 & 27 & 8643 & 535650 & $7 \%$ \\
\hline 9 & 32 & 60 & 10 & 420 & 1521 & 500417 & 20 & 13 & 25 & 27 & 8643 & 535650 & $7 \%$ \\
\hline 10 & 31 & 60 & 13 & 531 & 1963 & 576678 & 20 & 13 & 25 & 27 & 8643 & 611911 & $6 \%$ \\
\hline 11 & 30 & 60 & 12 & 831 & 1850 & 560211 & 15 & 16 & 30 & 26 & 10483 & 602945 & $7 \%$ \\
\hline 12 & 29 & 60 & 11 & 473 & 1731 & 540542 & 15 & 16 & 30 & 26 & 10483 & 583275 & $7 \%$ \\
\hline 13 & 28 & 60 & 11 & 469 & 1716 & 537852 & 15 & 16 & 30 & 26 & 10483 & 580585 & $7 \%$ \\
\hline 14 & 27 & 60 & 11 & 469 & 1716 & 537852 & 15 & 16 & 30 & 26 & 10483 & 580585 & $7 \%$ \\
\hline 15 & 26 & 60 & 11 & 469 & 1716 & 537852 & 15 & 16 & 30 & 26 & 10483 & 580585 & $7 \%$ \\
\hline 16 & 25 & 60 & 11 & 469 & 1716 & 537852 & 16 & 16 & 32 & 26 & 11182 & 583434 & $8 \%$ \\
\hline 17 & 24 & 60 & 11 & 469 & 1716 & 537852 & 17 & 16 & 34 & 26 & 11881 & 586283 & $8 \%$ \\
\hline 18 & 23 & 60 & 11 & 469 & 1716 & 537852 & 18 & 16 & 36 & 26 & 12579 & 589132 & $9 \%$ \\
\hline 19 & 22 & 60 & 11 & 469 & 1716 & 537852 & 19 & 16 & 38 & 26 & 13278 & 591981 & $9 \%$ \\
\hline 20 & 21 & 60 & 11 & 469 & 1716 & 537852 & 20 & 16 & 40 & 26 & 13977 & 594830 & $10 \%$ \\
\hline 21 & 20 & 60 & 14 & 533 & 1973 & 578100 & 20 & 16 & 40 & 26 & 13977 & 635077 & $9 \%$ \\
\hline 22 & 19 & 60 & 15 & 896 & 2112 & 595395 & 15 & 20 & 47 & 26 & 16136 & 661174 & $10 \%$ \\
\hline 23 & 18 & 60 & 16 & 599 & 2238 & 608505 & 15 & 20 & 47 & 26 & 16136 & 674284 & $10 \%$ \\
\hline 24 & 17 & 60 & 13 & 520 & 1921 & 570729 & 16 & 20 & 50 & 26 & 17212 & 640894 & $11 \%$ \\
\hline 25 & 16 & 60 & 13 & 520 & 1921 & 570729 & 16 & 20 & 50 & 26 & 17212 & 640894 & $11 \%$ \\
\hline 26 & 15 & 60 & 13 & 520 & 1921 & 570729 & 17 & 20 & 53 & 26 & 18288 & 645279 & $12 \%$ \\
\hline 27 & 14 & 60 & 13 & 520 & 1921 & 570729 & 18 & 20 & 57 & 26 & 19364 & 649664 & $12 \%$ \\
\hline 28 & 13 & 60 & 13 & 520 & 1921 & 570729 & 19 & 20 & 60 & 26 & 20439 & 654050 & $13 \%$ \\
\hline 29 & 12 & 60 & 13 & 520 & 1921 & 570729 & 19 & 20 & 60 & 26 & 20439 & 654050 & $13 \%$ \\
\hline 30 & 11 & 60 & 13 & 520 & 1921 & 570729 & 20 & 20 & 63 & 26 & 21515 & 658435 & $13 \%$ \\
\hline 31 & 10 & 60 & 13 & 520 & 1921 & 570729 & 22 & 20 & 69 & 26 & 23667 & 667206 & $14 \%$ \\
\hline 32 & 9 & 60 & 16 & 599 & 2238 & 608505 & 22 & 20 & 69 & 26 & 23667 & 704981 & $14 \%$ \\
\hline 33 & 8 & 60 & 16 & 930 & 2249 & 609579 & 15 & 25 & 74 & 26 & 24744 & 710448 & $14 \%$ \\
\hline 34 & 7 & 60 & 17 & 605 & 2261 & 610622 & 15 & 25 & 74 & 26 & 24744 & 711491 & $14 \%$ \\
\hline 35 & 6 & 60 & 14 & 556 & 2063 & 589658 & 16 & 25 & 79 & 26 & 26394 & 697251 & $15 \%$ \\
\hline 36 & 5 & 60 & 14 & 556 & 2063 & 589658 & 16 & 25 & 79 & 26 & 26394 & 697251 & $15 \%$ \\
\hline 37 & 4 & 60 & 14 & 556 & 2063 & 589658 & 17 & 25 & 83 & 26 & 28043 & 703976 & $16 \%$ \\
\hline 38 & 3 & 60 & 14 & 556 & 2063 & 589658 & 17 & 25 & 83 & 26 & 28043 & 703976 & $16 \%$ \\
\hline 39 & 2 & 60 & 14 & 556 & 2063 & 589658 & 17 & 25 & 83 & 26 & 28043 & 703976 & $16 \%$ \\
\hline 40 & 1 & 60 & 18 & 628 & 2351 & 618137 & 17 & 25 & 83 & 26 & 28043 & 732455 & $16 \%$ \\
\hline 41 & 0 & 60 & 18 & 334 & 2351 & 618137 & 17 & 25 & 83 & 26 & 28043 & 732455 & $16 \%$ \\
\hline
\end{tabular}




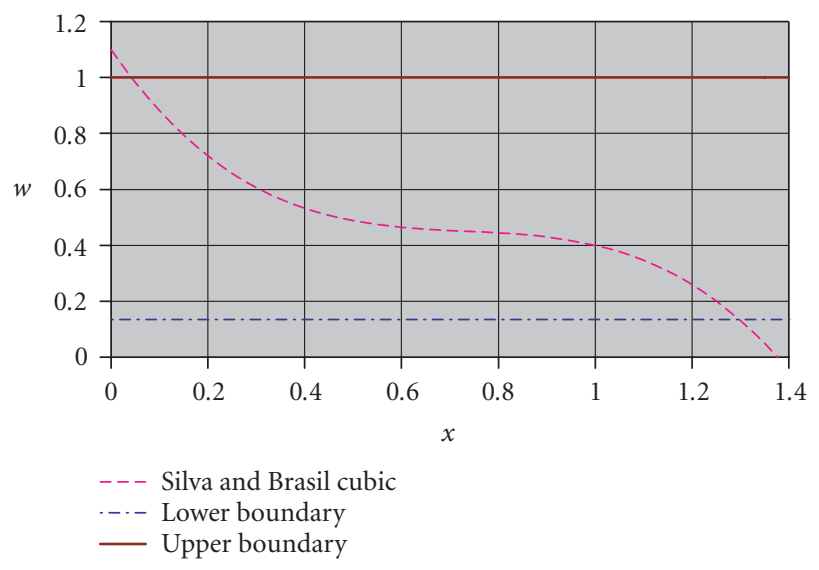

Figure 3.1. Effective stiffness adopted.

According to NBR-6123-87 [2], we consider the basic wind speed of $V_{0}=35 \mathrm{~m} / \mathrm{s}$, the topographic factor is $S_{1}=1$, terrain roughness category $I V$, class $B$, which gives $S_{2} \equiv$ ( $b ; p ; F_{r}$ ), and the statistic factor is $S_{3}=1.1$. As we stated before, the wind load on an area $A$ is $F=q \cdot C_{a} \cdot A$, where $C_{a}$ is the aerodynamical coefficient. Several equipments are installed on the structure, they are stairway with anti-falls cable, platform with antennas supports, night signer lights, protection against atmospheric discharges system, and installed antennas. The values of $A$ and $C_{a}$ are tower, $0 \leq z \leq 40 \mathrm{~m}, A=0.6 \mathrm{~m}^{2} / \mathrm{m}$, and $C_{a}=0.6$; stairways, $0 \leq z \leq 40 \mathrm{~m}, A=0.05 \mathrm{~m}^{2} / \mathrm{m}$ and $C_{a}=2$; cables, $0 \leq z \leq 40 \mathrm{~m}$, $A=0.15 \mathrm{~m}^{2} / \mathrm{m}$, and $C_{a}=1.2$; platform and antennas supports, $z=40 \mathrm{~m}, A=1 \mathrm{~m}^{2}$, and $C_{a}=2$; antennas, $z=40 \mathrm{~m}, A=3 \mathrm{~m}^{2}$, and $C_{a}=1$. Table 3.1 shows the nodal mass (M) and area for the structure analyzed.

Based on the results obtained by Brasil and Silva [1], in this section we adopt the following equation (Figure 3.1) for the effective stiffness parameters:

$$
w=-1.5 x^{3}+3.3 x^{2}-2.5 x+1.1, \quad w_{s} \leq w \leq 1, \quad \text { para } i=0,1, \ldots, n
$$

Note that the upper value is equal to 1.0 and lower values vary. Because of the safety coefficients adopted materials, and design process, usually in tests structures present values of $x=M_{k} / M_{u} \geq 1.0$. For a $30 \mathrm{~m}$ structure tested by Brasil and Silva [1], the maximum value assumed by $x$ was 1.33 and for other similar $40 \mathrm{~m}$ structure the maximum was $x=1.53$.

Considering the lumped mass $(\mathrm{M})$ given in Table 3.1, the total homogenized moment of inertia for the LDA model, and the effective moment of inertia of the final iteration of $P$-Delta method for the NDA, we compute the natural modes and frequencies of vibration (Figure 3.2). Note that in nonlinear model the frequencies are smaller than in LSA. The coefficient of amplification $\xi$ presented values until 2.35 for LDA and 2.65 for NDA. 


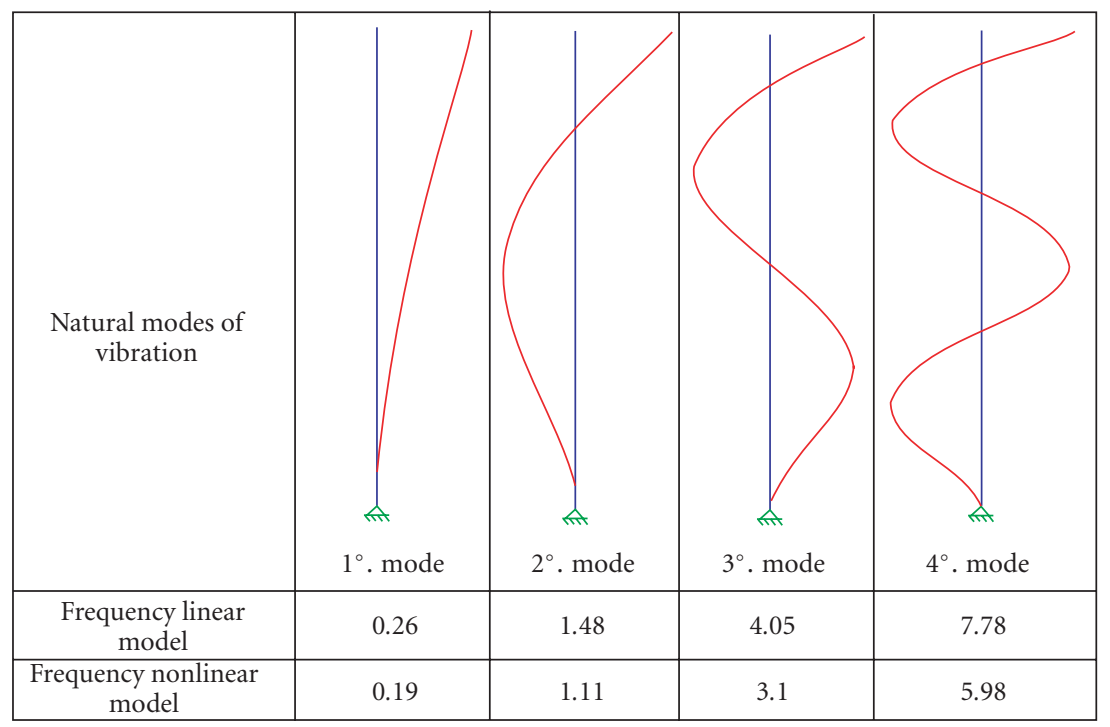

Figure 3.2. Natural modes and frequencies $(\mathrm{Hz})$ of vibration.

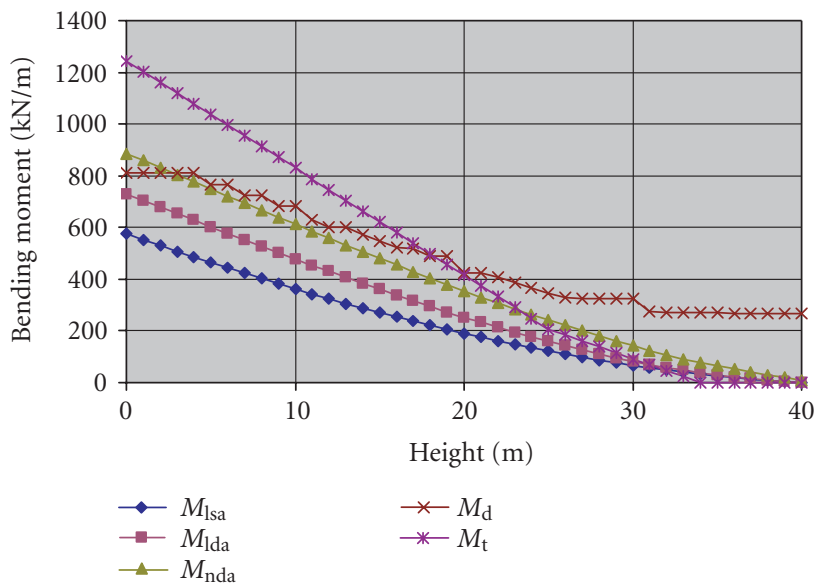

Figure 3.3. Bending moments.

The values obtained for bending moment in both models analyzed are shown in Figure 3.3. In this figure we can see the following bending moments obtained: $M_{\mathrm{lsa}}$ (LSA), $M_{\text {lda }}$ (LDA), $M_{\text {nda }}$ (NDA), $M_{\mathrm{d}}$ (design bending moment), and $M_{\mathrm{t}}$ (bending moment applied in tests). The LDA presented values of bending moment 1.3 times those given by the LSA, while the NDA presented values 1.5 times those from LSA. The design moments are 1.4 times those given by LSA and 1.1 times those given by LDA. Comparing the results we conclude that the design bending moment is satisfactory to the LDA, but is not 
satisfactory for NDA. Other important conclusion is about the excellent performance of the structure related to the safety coefficient near to failure. The structure resisted a load around 1.53 times the design moment. As we stated before, this is due to the safety coefficients applied on material strength. Results from tests show that the structure resists satisfactorily the bending moments given by NDA.

Other important considerations here are related to the elasticity modulus of concrete. In this work we considered $E=41.4 \mathrm{GPa}$, computed according to NBR-6118-78 (ABNT [3]) Brazilian code. This value is larger than the values measured in tests, around $21 \mathrm{GPa}$, and larger than the value given by the revision of that code, the new NBR-6118-03 (ABNT [4]), around $31.9 \mathrm{GPa}$ for the adopted concrete. Tests showed that when we compute a certain function $w_{1}(x)$ considering a given elasticity modulus of concrete $E_{1}$ and solve the problem again using another value $E_{2}$, the new value of $w$ is $w_{2}(x)=E_{1} w_{1} / E_{2}$, in other words, the quantity $E_{1} w_{1}=E_{2} w_{2}=E_{i} w_{i}$ is a constant for different values of $E$ adopted.

\section{Conclusions}

In this work we propose a nonlinear dynamic model based on experimental data and the discrete dynamic model given by NBR-6123-87 [2]. We adopted the effective stiffness concept to represent the physical nonlinearity and used a $P$-Delta method to compute the geometrical nonlinearity. We considered a cubic equation to represent the effective stiffness. We accomplished the NDA considering the effective stiffness in function of the strength level in each iteration of the $P$-Delta method. The effective stiffness obtained in the final iteration of the $P$-Delta method was used to compute the natural frequencies and modes of vibration. We considered that the structure displaces around the equilibrium position given by the $P$-Delta method. Finally, we computed the sum of nonlinear static and dynamic strength. We compared the values obtained from the NDA with those from the LSA and the LDA. The LDA presented values of bending moment 1.3 times those given by the LSA, while the NDA presented values 1.5 times those from the LSA. The design moments are 1.4 times those given by the LSA and 1.1 times those given by the LDA. We conclude that the design bending moment is satisfactory to the LDA, but is not satisfactory for the NDA. Results from tests show that "in practice" the structure resists satisfactorily the bending moments given by the NDA.

Suggestions for future works are

(i) process this structure considering different equations for the effective stiffness;

(ii) accomplish this NDA using the synthetic wind method (Franco [5]).

\section{References}

[1] R. M. L. R. F. Brasil and M. A. Silva, RC large displacements: optimization applied to experimental results, Proceedings of the Seventh International Conference on Computational Structures Technology, Lisbon, 2004.

[2] ABNT - Associação Brasileira de Normas Técnicas, NBR-6123-87: Forças Devidas ao Vento em Edificações, 1987 (Portuguese).

[3] ABNT - Associação Brasileira de Normas Técnicas, NBR-6118-78: Projeto e Execução de Obras de Concreto Armado, 1978 (Portuguese). 


\section{Nonlinear dynamic analysis}

[4] ABNT - Associação Brasileira de Normas Técnicas, NBR-6118-03: Projeto de Obras de Concreto, 2003 (Portuguese).

[5] M. Franco, Direct Along-Wind Dynamic Analysis of Tall Structures, Boletim Técnico da Escola Politécnica da Universidade de São Paulo, BT/PEF/9303, 1993.

Marcelo A. Silva: Department of Structures and Foundations Engineering (PEF/EPUSP), Polytechnic School, University of Sao Paulo, Rua Parnamirim 97, A24, CEP 05.331-020, Sao Paulo, Brazil

E-mail address: m_araujo_silva@uol.com.br

Reyolando M. L. R. F. Brasil: Department of Structures and Foundations Engineering (PEF/EPUSP), Polytechnic School, University of Sao Paulo, Rua Parnamirim 97, A24, CEP 05.331-020,

Sao Paulo, Brazil

E-mail address: rmlrdfbr@usp.br 


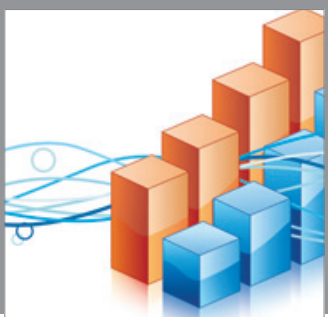

Advances in

Operations Research

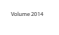

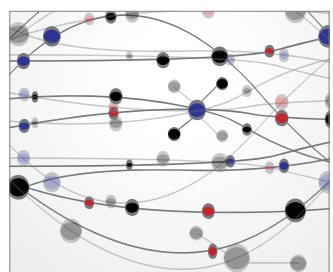

\section{The Scientific} World Journal
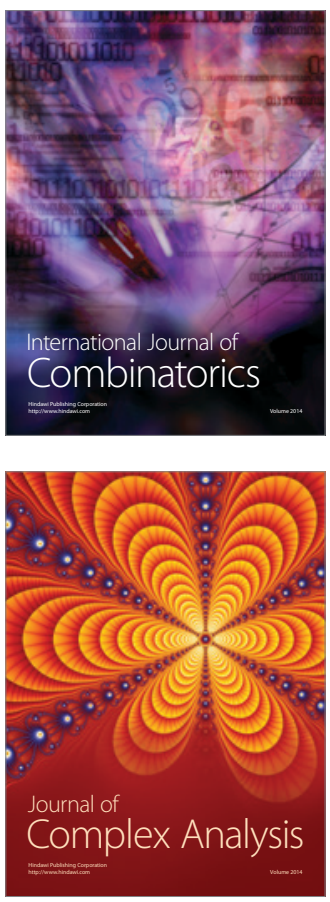

International Journal of

Mathematics and

Mathematical

Sciences
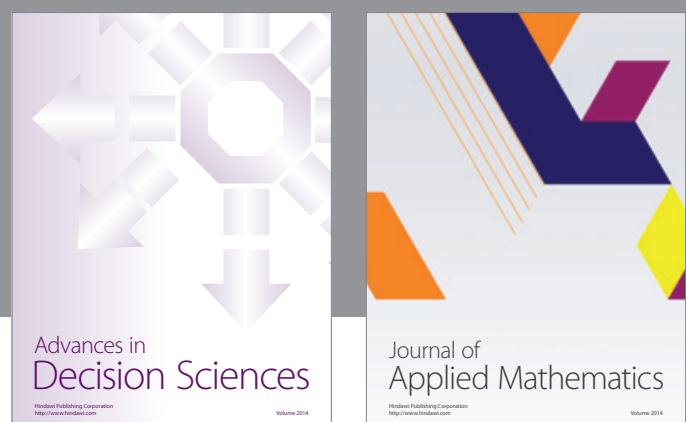

Journal of

Applied Mathematics
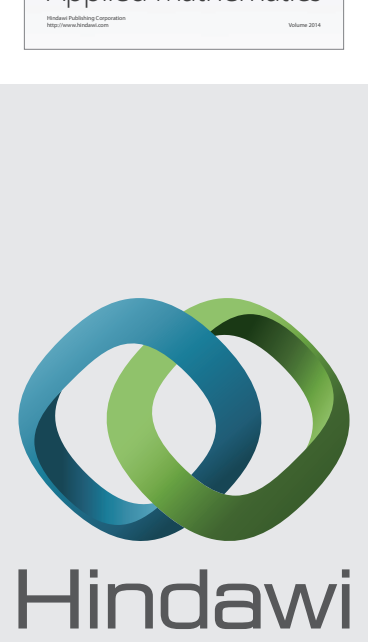

Submit your manuscripts at http://www.hindawi.com
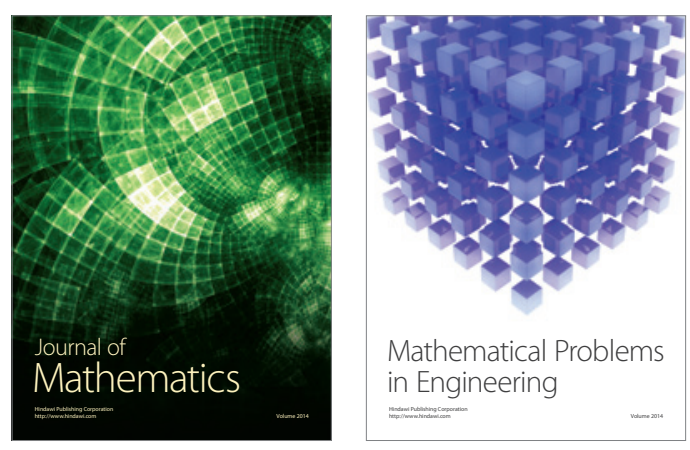

Mathematical Problems in Engineering
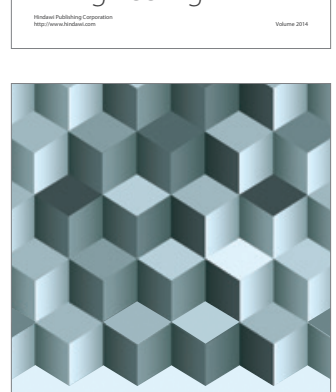

Journal of

Function Spaces
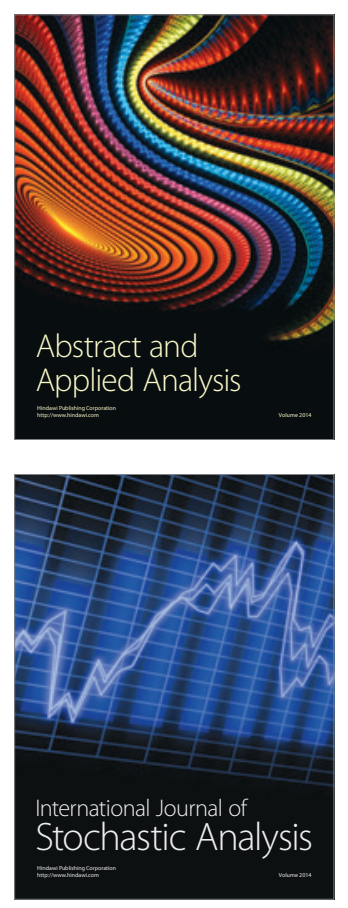

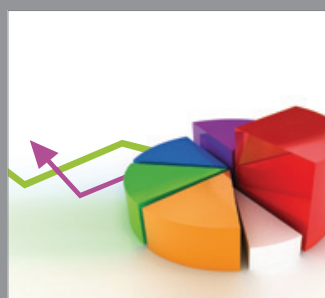

ournal of

Probability and Statistics

Promensencen
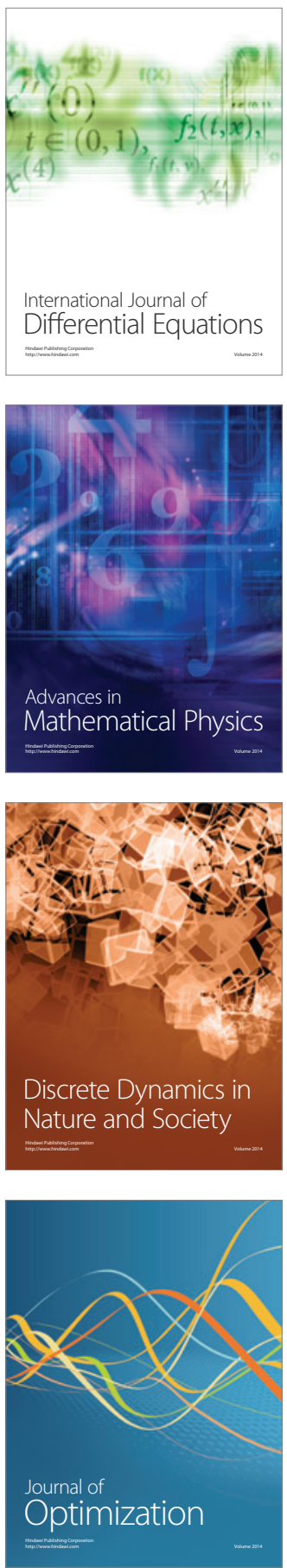